\title{
The new BMW: business model innovation transforms an automotive leader
}

\section{Prasanna Kumar Kukkamalla, Andrea Bikfalvi and Anna Arbussa}

\author{
Prasanna Kumar \\ Kukkamalla is based at the \\ Department of \\ Organization, Business \\ Management, and Product \\ Design, University of \\ Girona, Girona, Spain. \\ Andrea Bikfalvi and Anna \\ Arbussa are both based at \\ the Department of Business \\ Administration and Product \\ Design, University of \\ Girona, Girona, Spain.
}

(c) Prasanna Kumar Kukkamalla, Andrea Bikfalvi and Anna Arbussa. Published by Emerald Publishing Limited. This article is published under the Creative Commons Attribution (CC BY 4.0) licence. Anyone may reproduce, distribute, translate and create derivative works of this article (for both commercial \& noncommercial purposes), subject to full attribution to the original publication and authors. The full terms of this licence may be seen at http://creativecommons. org/licences/by/4.0/legalcode

\begin{abstract}
Introduction
Technological innovations, market dynamics and changes in customer preferences have greatly impacted the traditional business model of manufacturing firms. While many firms struggle to generate a substantial profit from product sales, others try to identify opportunities by integrating product-related and value-added services. The days are gone when firms focused solely on product-centric business. A new business strategy known as service integration has evolved in the manufacturing sector. Changes happen at the level of value creation, value delivery and value capture. Any change in these dimensions ultimately results in business model innovation which is defined as an activity or process in which core elements of an enterprise and its business rationale are purposely transformed to achieve operational and strategic advancements.
\end{abstract}

The innovation in business models is novel and complex in nature, and it connects with various aspects such as corporate strategy, technological capabilities and firms' innovation processes. Business models are periodically impacted by technological innovations either by creating an opportunity or by taking a risk which will result in competitive advantage or disruption. Business model innovation is often the result of external factors such as competition law, labour market legislation and environmental legislation. The automotive industry has long been applying the traditional model. The value of this kind of model depends on being able to offer more cost-effectiveness, low emission engines and extra safety packs that may include auto-braking and chassis control, among others (Chrysakis, 2017). However, these features no longer create competitive advantages, and they have proved easy to copy. Many car manufacturing firms have lately integrated or are planning to integrate customer services such as mobility services, on-demand services and infotainment services in their core business operations. While practitioners and research communities have paid much attention to business model innovation, an industry-specific model, for example how car manufacturers orchestrate their business model and which elements are impacted by this change, is yet to emerge. To fill this knowledge gap, we narrow down the research on innovation in business models by focusing attention on BMW, considered to be one of the leading industry players for advanced services and a successful business model innovator.

The structure of this article is as follows: first, this study explores the business model literature to outline the factors impacting innovation, and a framework for the business model innovation process is proposed. This framework is then used to discuss each element of the business model related to ConnectedDrive and the corresponding degree of innovation. Last, the paper compares the traditional and service integrated business models, as Figure 1 shows. 


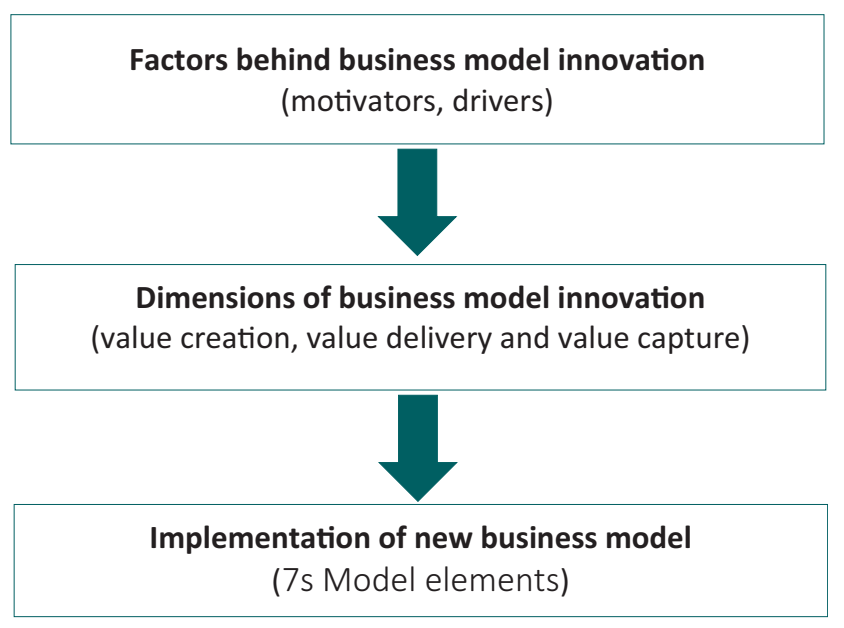

The factors behind business model change

A set of factors was synthesised and classified into two groups (Figure 1): motivators (inspire the firm) and drivers (facilitate change).

\section{Motivators}

Change can be triggered by internal factors such as organisational culture, the firm's aspirations, management support and new revenue channels, or by external factors such as market pressure for innovation and differentiation.

\section{Drivers}

Different factors can facilitate the innovation process, including market-level factors such as information and communication technologies (ICTs), big data, external drivers (globalisation, deregulation), the ability of firms to identify changes, co-development relationships, stakeholder demands, knowledge management infrastructure and management processes.

\section{Dimensions of innovation}

Rayna and Striukova (2016) find five dimensions of value in the business model literature: creation, proposition, capture, delivery and communication. This article discusses three of the most relevant values to the case study: creation, delivery and capture.

\section{Value creation}

Firms create value for the product and services with their core competencies, key resources, governance, complementary assets and value networks.

\section{Value delivery}

This dimension describes how the value created is delivered to customers through distribution channels These elements offer ample opportunity for innovation by addressing the needs of the market segment (for instance, a mobility service that targets short term 
travel needs), or by introducing a new way to deliver products or services (for instance, Netflix or Amazon Prime).

\section{Value capture}

This refers to the firm's ability to benefit from the value created. It includes the revenue model used to generate cash flow and the cost structure. Value capture also includes profit allocation across the value chain. Innovation may allow a firm to gain market leadership through cost restructuring.

\section{Degree of innovation}

Changes in the elements of the business model influence the degree of innovation. Amit and Zott (2012) categorise innovation as radical or incremental. Radical innovation is an innovation with a high degree of novelty, which breaks with what existed previously. John Deere, for example, has revolutionised the farming industry by integrating sensor technology into its tractors. In contrast, incremental innovation has a low degree of novelty, and with less risk and cost than radical innovation. For instance, electric windows, air bags, cup holders and ABS brakes are all examples of the incremental innovations made to cars.

\section{Case background}

BMW is one of the leading firms in the automotive industry, not only offering premium vehicles but for many years also providing customer with financial, on-demand and telematics services. The firm's transformation to customer-centric began by introducing telematics services in 1997. For the past 22 years, BMW has not only been offering telematics services, but has become the dominant force in the digital service market. The range of services available for current BMW models includes a personal telephone information service, emergency calls, Google Local Search, traffic information and internetbased services for navigation, communication and infotainment. These services are available in 45 countries, and there are already over 10 million connected BMW vehicles on the world's roads.

\section{Methodology}

For this research, a single case study method was used. The case study research method as described by (Yin, 2003) is a suitable method for obtaining insights into the innovation approach. This study follows the document analysis technique (Bowen, 2009), a systematic procedure for reviewing and evaluating both printed documents and digital material. It is especially applicable to qualitative case studies, which are intensive analyses that produce rich descriptions of a single phenomenon, event, organisation or programme (Stake, 2000; Yin, 1994). The data was gathered from BMW press releases, websites, annual reports, company announcements and collaboration announcements.

\section{Findings}

\section{Factors behind innovation}

Motivators. Three motivators behind BMW's decision to change its product-centric model to a service model were identified. These are organisational culture, competitive advantage and additional revenue (Table 1). Regarding organisational culture, as a pioneer in the market, BMW always strives to be innovative in its core business activities. With aspirations of being a pioneer in technology and a first mover in the market, in 1997 BMW launched internet services in the car (telematics service). BMW has kept its commitment to offer more customer-centric solutions, expressing its organisational culture in the following ways: "we 
Table 1 Factors behind business model innovation

\begin{tabular}{lll} 
Classification & Factors & Explanation \\
\hline Motivators & Organisational culture & Shared assumptions, values and beliefs \\
& Competitive advantage & Unique, high demand, or superior quality products or services \\
Additional revenue & Revenue from additional services \\
& Technology integration & Use of technology tools to enhance service quality or portfolio \\
& Collaborations & Association with other organisations to achieve goals \\
& Dynamic capabilities & Ability to integrate, build and reconfigure internal and external competences \\
& Knowledge process & Method for creating, acquiring and using knowledge
\end{tabular}

committed", "as promised", "being a first mover" and "technology pioneer". The integration of services of this kind prompted the start of change in its business model.

The increase in competition from emerging markets and dynamic market conditions has led car manufacturing firms to focus more on innovations. In 1997, the digital service market was in the expansion stage, and there were not many players in the market. BMW used this opportunity to create a competitive advantage for their fleets. Twenty years in telematics services have proved their strategy to be successful, and BMW has kept its leading position in the digital service market. Creating a competitive advantage is one of the reasons behind innovation.

Light vehicle production on a global basis dropped during the 1998 calendar year, falling nearly two per cent to 51.6 million units. This decline, starting in 1997, stemmed from the collapse of the Asia-Pacific region economies where automotive output declined by $11 \%$ to 14.5 million units.

To create additional revenue streams, BMW introduced digital services into the market. Inservice integration model firms generate revenue by providing customer solutions and creating new revenue channel sources (Liang et al., 2017). This could have been one possible motivation for BMW to change to a service-based firm. One vice-president described this movement: "We build digital products and services that are meant to help us differentiate our core product, the car, and generate revenue." These services have been offered for several years, but the firm does not reveal its exact revenue from these services. Information gleaned from the annual reports and the expansion of third-party services in the digital service platform indicate that BMW receives a substantial amount of revenue from these services. Aspirations of additional revenue is obviously one of the factors behind the change.

Drivers. Regarding the drivers that facilitated the change, BMW relied on technology integration, collaborations, dynamic capabilities and knowledge process activities. IT (information technology) firms have expanded their business into the automotive industry landscape, offering customer services such as parking payments and in-vehicle services. With their dominant technological knowledge and market power, they disrupt the business model of the automotive industry. In this competitive situation, instead of competing with each other, BMW teamed up with these firms. A board member commented on this move: "We cannot offer clients the perfect experience without help from one of these technology companies. Two worlds are colliding here. Our world focused on hardware and our experience in making complex products, and the world of information technology, which is intruding more and more into our life".

Given that the telematics service business seemed to be taking off, BMW escalated the service integration process by making collaborative agreements with various stakeholders such as technological firms and telecommunications providers. Instead of developing the technology itself, the company opted for a collaborative strategy to access a partner's service and to provide an opportunity to integrate services as third-party service suppliers. 
For example, the firm has developed central engine control units through cooperation with partners such as Bosch and Siemens.

To sum up, the firm's key motivation behind these collaborations was not simply to integrate the partner's services but to select only innovative technology and widely accepted solutions in the market such as on-demand music and navigation services.

With regard to dynamic capabilities, in an online interview lan Robertson, member of the Management Board BMW AG, pointed out that "We are one of the world's, if not the, most successful automotive companies and we are rapidly becoming a technology company". In line with this vision, BMW has developed new capabilities such as the ability to integrate, build and reconfigure internal and external competencies to address rapidly changing environments. In 2001, the BMW Group Launched VIA 2.0 (The Virtual Innovation Agency), the online platform for people with ideas. All ideas, concepts and patents for new technologies that could be used by the BMW Group in its products and services in the short, medium and long term can be submitted online.

Effective knowledge process activities accelerate the change process. These activities include the capture, transformation and use of knowledge to design new services (Ansari et al., 2012). BMW generates a huge amount of data about vehicle conditions, drivers' behaviour, and user service preference through the digital service platform. This data is processed by the firm and/or supply chain partner to design and develop new services. These (data collecting) processing activities serve BMW's legitimate interest in meeting the high standards placed by customers on existing products and services and being capable of satisfying customers' future wishes through the development of new products and services (Data protection, BMW). BMW has associated with leading technology centres in Europe, Japan and the USA, immediately entering all the knowledge and information gained into a central Intranet system made available to all associates to promote new ideas and networked thinking.

\section{Traditional business model vs service business model}

Press notes and media announcements made by BMW were analysed to present the two models. One is the traditional model (Car as a product) and the other is a new model (Car as a service). The first still exists in the company and the new model is being built for ConnectedDrive services (Table 2). Analysis of the business model reveals different views, one traditional and the other new.

In the traditional model, value creation is based on the firm's resources, capabilities and activities. Sometimes key resources are acquired from the supply chain network, but within the automotive business landscape. Meanwhile, in the new model, value comes from integration technology (established in the market or new to the market), knowledge process activities (customer knowledge) and collaborations (mostly IT firms).

In the traditional model, the firm uses dealer networks and their own distribution channel to deliver the product (car). The customer segment is mostly people who love luxury products, fuel-efficiency and design. However, in the new model, BMW uses its own network (store and online) to deliver services. BMW mainly targets people who love digital services. In the traditional model, BMW generates income through the sale of products and spare parts. Other basic services like maintenance and insurance also contribute a substantial amount of revenue. Most of the cost structure in the traditional model involves R\&D, production, sales and marketing and training. In the new model, BMW has created various pricing models to generate revenue such as Freemium and Subscription mode (bundle and flexible). They invest money in activities such as service design, technology acquisition and knowledge management. 


\section{Table 2 Comparison of business model components - car as a product vs car as a service}

Car as a product model

Value creations

Key resources

Key activities

Key partners

Customer

relationship

Value delivery

Channels

Customer

segment

Value capture

Revenue

streams

Cost structure

People and technology Research institutes people Insurance premium
Production, Sales and Marketing R\&D, Training

Supply chain network Insurance firms, Designers,

Maintenances, customer service assistance

Dealers and traditional car distributors/stores Urbanites, Performance driven, quality-minded

Car sales service and maintenance

R\&D, Productions, Sales and marketing
Car as a service model

Partner's resources, customer knowledge

Service designing, Knowledge management

Other firms, (music providers, navigation service providers, telecommunication firms)

Feedback and reviews, Social media interaction

Own network (app store, customer office)

Tech-savvy consumers

Subscription fee service fee

(Bundle and flexible)

Service design, technology acquisition cost and knowledge management activities

Source: Author's own elaboration

\section{Implementation of a new business model}

The study explored BMW's new business model implantation process through McKinsey's 7S Framework (Waterman et al., 1980). The model is often used as an organisational analysis tool to assess and monitor changes in the internal environment of the firm. The findings are discussed through seven aspects of BMW that align for the successful integration of digital services and expansion of ConnectedDrive services: structure, strategy, systems, skills, style, staff and shared values (Figure 2).

\section{Structure}

This defines how a firm is organised for transformation. The automobile industry has expanded into a digital service ecosystem. External factors such as the evolution of digital

\section{Figure 2 Illustration of business model Implementation through McKinsey 7 s model}

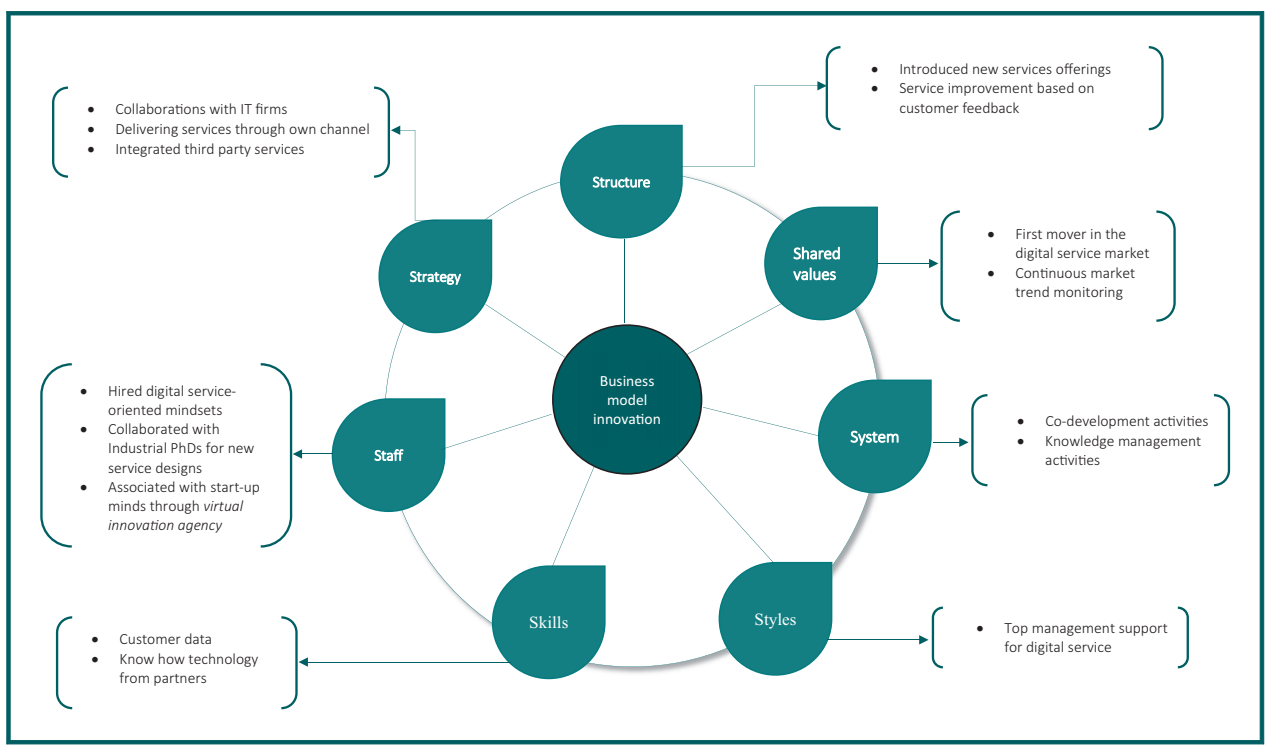


services, customer preferences and market trends have led BMW to focus on digital services. BMW introduced these services in 2008 , and they have gradually expanded over the years. The company continually monitors these service adaptabilities in the market and improves them based on customer reviews and feedback. This observation emphasises the fact that for effective transformation a firm needs to focus on external elements such as market trends and customer preferences. Firms also need to focus on customer complaints, reviews and feedback to improve service quality.

\section{Strategy}

Strategy is the way a firm aims to improve its position through better value for its customers. BMW adopted technologies that are well accepted in the market and integrated into their service portfolio. Chesbrough and Schwartz (2007) argue that firms can innovate the business model by establishing co-development relationships with different stakeholders. Along with their own digital services, after collaborations. BMW started third-party services in a digital service network. The reason behind these third-party service integrations was that customers like technologies such as apply play, on-demand music and navigation services while driving. BMW set up its own digital platform to deliver its services to customers who can acquire them through the website and the App Store. The results showed that BMW adopted a collaborative strategy with established IT firms.

\section{System}

Systems are defined as all the procedures, both formal and informal, that make the organisation perform better. BMW's digital services emerged from the innovation of elements in the business model. Innovation started with changing the key activities of the firm. BMW set up a 24/7 customer service centre to answer all enquiries related to ConnectedDrive services, where customers can interact with the service provider through social media. In March 2019, the firm also introduced an intelligent personal assistant to help drivers with driving-related issues. These kinds of activities lead to generating customer information and related knowledge. In addition, BMW also involves customers in early customer service designing processes. This innovative step enables a more collaborative relationship with customers as a way of meeting customer expectations.

\section{Staff}

In 2014, BMW appointed Dieter May as senior Vice-President for digital products and services to lead the way in staff. At that time, he had had 23 years' experience in global high-tech companies, spanning mobile products, large-scale cloud-based consumer services and semiconductor technology. BMW also invited creative ideas for products and services through the "Virtual Innovation Agency". The company associated with selected people for service development, and with several research units and start-ups for new service developments, for instance offering industrial $\mathrm{PhDs}$ where researchers develop products and services for BMW. A general manager of product and channel development at BMW Group UK commented: "BMW opened its doors to external entrepreneurs to partner with them to support our innovation plan. This way we develop new services that tackle the changing customer needs we are seeing, and they help us find new ways to capitalise on new technologies". This observation showed that for an effective transformation a firm should take advantage of experienced personnel and associate with creative minds.

\section{Style}

Style refers to how management acts in achieving the organisation's mission within the cultural context of the firm. BMW is one of the first movers in the digital services market, 
striving to be a market leader and pioneer in the digital service business. A general manager of product and channel development at BMW commented: "You need to learn to get from idea to implementation quickly. It's something we strive to do. And BMW's commitment to innovation across our business is coming from the very top of the company our executive team see this as a key part of their strategy for the business". Another factor observed in this study is that BMW clearly defined its transformation and new image in the market. The vice-president of digital services and business models commented: "The BMW Group is working to shift from a traditional luxury auto manufacturer and service provider to a technology company, with automated driving, digital connectivity, mobility services and electrification as some of the central pillars of our new strategy". The results show that the firm needs support and cooperation for transformation, and they must have a clear vision of where this transformation is leading.

\section{Skills}

Skills are the organisation's dominant attributes, competencies and capabilities. BMW established the capabilities required for digital services, which include sensing, identifying and assessing emerging opportunities. Establishing these capabilities is completely new in the automotive industry. First, the company hired experienced people to lead the digital services business. It then associated with established IT firms and other firms to acquire know-how technology and competences. For instance, BMW acquired analytical capabilities by teaming with IBM. IBM's cloud platform Bluemix gives developers access to BMW's entire service catalogue and its ecosystem partners to build and operate innovative new service offerings. The general manager of IBM explained this collaboration: "The concept of a neutral server fosters innovation by establishing a single point of contact for multiple parties to access vehicle data from various manufacturers, thereby reducing integration cost whilst ensuring fair competition". The results showed that BMW acquired skills and competencies from IT partners. Some competencies are co-developed with partners. To sum up, for effective new business model implementation a firm needs to develop and acquire skills and capabilities.

\section{Shared value}

Shared value is defined as the norms and standards that guide a firm's action, or the core vision of the firm. Creating a digital environment for drivers is the core vision of ConnectedDrive services. The vice President of Digital Products and Services expressed this vision as: "We build digital products and services that are meant to help us differentiate our core product, the car, and generate revenue. These digital services also provide us with channels and touch points that allow us to now have a direct relationship with the customer on the sales side and talk to the customer directly". BMW's mission for ConnectedDrive services is to establish better customer relationships and new revenue streams.

\section{Conclusion}

The aim of the present study is twofold: first, to examine a business model innovation framework with influencing factors and to contrast it with empirical evidence. This goal was achieved by presenting a conceptual framework and applying it as an analytical tool to describe BMW's model development. Second, this research showed how BMW innovates each element in the model dimensions, which were then categorised into various degrees of innovation. The study also showed how BMW orchestrates innovation for digital services. To effectively adopt changes in the business model, the firm must first clearly understand what motivates this transformation. The firm should focus on factors such as market dynamics and other external forces that influence business landscapes. However, the firm should be aware that these forces can create an advantage or risk. Motivation alone is not 
Keyword:

Business model innovation enough to change the model, but the firm should find drivers that facilitate this transformation. The firm must have the support of these drivers to create an efficient model.

Market dynamics have changed dramatically, and the firm needs to develop dynamic capabilities to shape business activities according to demand. Firms cannot create value through their products or services alone but rather need to collaborate with other stakeholders to create a value constellation, as suggested by Haggège et al. (2017). By adopting the latest technology, constant service-integration and customer knowledge can transform business activities to be more efficient and effective.

This paper has some limitations. The first one is that it develops a conceptual framework with the factors that emerged from the literature and are validated with a signal case study. The second limitation is that the study depends solely on secondary data. Regarding future research directions, this study recommends that research communities validate the proposed framework in a different context and with multiple case studies. The key element category presented in this study should be expanded further through empirical analysis.

The business model literature focuses on the impacts and benefits in general, proposing strategies for innovation. However, context-specific studies are yet to be uncovered. As a result, empirical illustrations of business model innovation in the automotive industry are lacking. This study contributes by highlighting the issue through presenting the business model of BMW for digital services. The results of this study can help managers to understand how innovation in business models may be orchestrated and what elements they need to focus on.

\section{Acknowledgments}

An earlier version of this article has been presented at the 4th International Conference on New Business Models "New Business Models for Sustainable Entrepreneurship, Innovation, and Transformation", ESCP Europe Berlin, 1-3 July 2019, Berlin, Germany. The corresponding author would like to express his gratitude to the Department of Business Administration and Product Design, University of Girona (Spain) for financial support for the conference. The corresponding author would also like to thank his colleagues in the Centre for Research on Operation, Projects and Services (CROPS), Tampere University, and colleagues in the Department of Business Administration and Product Design, the University of Girona for their thoughtful and valuable comments.

\section{References}

Amit, R.H. and Zott, C. (2012), "Business model innovation: creating value in times of change", SSRN Electronic Journal, available at: https://doi.org/10.2139/ssrn.1701660

Ansari, M., Youshanlouei, H.R. and Mood, M.M. (2012), "A conceptual model for success in implementing knowledge management: a case study in Tehran municipality", Journal of Service Science and Management, Vol. 5 No. 2, available at: https://doi.org/10.4236/jssm.2012.52026

Bowen, G.A. (2009), "Document analysis as a qualitative research method", Qualitative Research Journal, Vol. 9 No. 2, pp. 27-40, available at: https://doi.org/10.3316/qrj0902027

Chesbrough, H. and Schwartz, K. (2007), "Innovating business models with co-development partnerships", Research Technology Management, available at: https://doi.org/10.1080/08956308.2007.11657419

Chrysakis, I. (2017), "How the digital business model can transform and boost the car industry", from ERCIM NEWS 109, available at: https://ercim-news.ercim.eu/en109/special/how-the-digital-businessmodel-can-transform-and-boost-the-car-industry (accessed 20 November 2019).

Haggège, M., Gauthier, C. and Rüling, C.C. (2017), "Business model performance: five key drivers", Journal of Business Strategy, Vol. 38 No. 2, available at: https://doi.org/10.1108/JBS-09-2016-0093

Liang, L., Xie, J., Liu, L. and Xia, Y. (2017), "Revenue sharing contract coordination of wind turbine order policy and aftermarket service based on joint effort", Industrial Management \& Data Systems, Vol. 117 No. 2, pp. 320-345, available at: https://doi.org/10.1108/IMDS-03-2016-0088 
Rayna, T. and Striukova, L. (2016), "360 Business model innovation: toward an integrated view of business model innovation", Research Technology Management, available at: https://doi.org/10.1080/ 08956308.2016.1161401

Stake, R.E. (2000), "Case studies", in Denz, N.K. (Ed.), Handbook of Qualitative Research, pp. 435-454, available at: https://doi.org/10.1258/096214400320575624.

Waterman, R.H., Peters, T.J. and Phillips, J.R. (1980), "Structure is not organization", Business Horizons, Vol. 23 No. 3, pp. 14-26, available at: https://doi.org/10.1016/0007-6813(80)90027-0

Yin, R.K. (1994), "Case study research: design and methods", Applied Social Research Methods Series, Vol. 5, p. 219, available at: https://doi.org/10.1097/FCH.0b013e31822dda9e

Yin, R.K. (2003), Case study research: design and methods. Case study research design and methods. Sage.

\section{About the authors}

Prasanna Kumar Kukkamalla is a Doctoral Candidate at the Department of Organization, Business Management and Product Design, University of Girona, Spain. His research interests focus on business model, organisational transformation, servitisation and service design. Prasanna Kumar Kukkamalla is the corresponding author and can be contacted at: prasanna@aol.in

Andrea Bikfalvi is teaching and a Research Staff, 'Serra Húnter Fellow' since 2018 at the University of Girona in Spain. During her trajectory, she conducted several research projects for the regional Government of Catalonia, Spain, as well as a series of EU projects. She visited and actively collaborates with researchers in relevant research centres and Higher Education Institutions in Germany, Finland, Croatia, Portugal, etc. Her main research interest is in holistic approaches of innovation in all types of organisations - mainly, but not limited to - public administration, private enterprises and education. Her expertise is in strategy, organisational innovation and business model configuration.

Anna Arbussa is an Associate Professor at the Department of Business Administration and Product Design of the University of Girona. She received her PhD from the same institution in 2001. She has worked on various European projects on electronic payments systems and published articles in the field of technological innovation and technology management. She is currently also working on public health management and on human resources management.

For instructions on how to order reprints of this article, please visit our website: www.emeraldgrouppublishing.com/licensing/reprints.htm

Or contact us for further details: permissions@emeraldinsight.com 